\title{
A metaheuristic for the time-dependent vehicle routing problem considering driving hours regulations - An application in city logistics
}

\author{
Nicolas Rincon-Garcia ${ }^{a}$, Ben Waterson ${ }^{b}$, Tom J. Cherrett ${ }^{b}$, Fernando Salazar-Arrieta ${ }^{c}$ \\ a Faculty of Engineering, Pontificia Universidad Javeriana, Bogotá, Colombia \\ b Transportation Research Group, University of Southampton, United Kingdom \\ c Faculty of Economic and Management Sciences, Pontificia Universidad Javeriana, Bogotá, \\ Colombia
}

This is the Author-Version of the paper published in Transportation Research Part A.

10.1016/j.tra.2018.10.033

\begin{abstract}
A B S T R ACT:
New retail trends show the increasing importance of providing cost efficient deliveries in cities, where congestion and compliance with driving hours regulations should be incorporated into routing software. This paper introduces a large neighbourhood search algorithm that substantially improves the benchmark solutions for the vehicle routing problem variant considering time windows, time-dependent travel times and driving hours regulations (EC) 561/2006 that apply to vehicles over 3.5 tons in European cities in terms of required number of vehicles, travelled distance and duty time. Additionally, instances for The Road Transport (Working Time) Regulation 2005 that applies to drivers in the United Kingdom are introduced. The proposed algorithm is also used in scenarios that represent home delivery conditions to evaluate the impacts of the length of time windows, customer density, congestion and regulations in terms of cost and environmental impact.
\end{abstract}

Keywords: time-dependent vehicle routing problem, rules on driving hours, driving time regulations, home delivery, city logistics, large neighbourhood search.

\footnotetext{
1. Introduction

New challenges are being faced by logistics providers; road congestion and the policy intended to improve road safety regarding driving time for drivers are issues that increase transportation costs and the complexity of generating efficient routes for vehicles. Underestimation of travel times as a consequence of congestion is the most commonly reported problem by transport managers (Eglese, Maden, \& Slater, 2006; Ehmke, Steinert, \& Mattfeld, 2012); the impact of congestion has increased over the last 30 years, with the 101 largest US cities reporting that travel delays had increased from 1.1 billion hours in 1982 to 4.8 billion hours in 2011 (Chang, Lee, \& Choi, 2015). Worldwide policy to increase road safety and improve working conditions for the freight industry has led to the introduction of hours of service regulations; driver fatigue is internationally recognized as a significant factor in approximately 15\%-20\% of commercial vehicle collisions (Goel \& Vidal, 2013). Therefore, the importance of understanding and developing technologies to support route schedulers to minimize the financial impact of these challenges, logistics operations are specifically designed to support a certain business model that should consider multiple factors, this paper studies the last mile problem in urban environments considering road congestion and the driving time regulation that applies to member states of the European Union.

Constant customer demands and the move to same-day delivery has meant that logistics providers have had to continually improve their level of service (Ehmke et al., 2012). The continuous growth of e-commerce and home delivery over the last 16 years imposes new requirements on the industry (Visser, Nemoto, \& Browne, 2014). In the case of required customer presence or signature, more accurate schedules are needed, and
} 
dispatchers and drivers often complain about their inaccuracy due to underestimation of travel times (Eglese et al., 2006; Ehmke et al., 2012). Current retail trends suggest that online sales represent $14 \%$ of all UK brick-andmortar stores and e-commerce; this is expected to increase to 35\% by 2020 (Javelin-Group, 2011; Visser et al., 2014), and it is estimated that $12 \%$ of first-time deliveries fail (Visser et al., 2014). This situation has drawn attention to certain issues in the last mile of the supply chain when the product is delivered to the customer; this is generally considered to be one of the most expensive, least efficient and most polluting parts of the supply chain (Gevaers, Van de Voorde, \& Vanelslander, 2011).

Some of the issues focus on the security aspects regarding secure places to leave packages, the absent consignee problem when the customer is required to sign, and a lack of critical mass to achieve economies of scale that make an operation profitable (Boyer, Prud'homme, \& Chung, 2009; Gevaers et al., 2011). Although there are many successful business examples with delivery to customers, such as Ocado (grocery delivery) and Office Depot (office supply delivery), and package logistic providers, such as UPS, there are many recorded failures such as Webvan, the online grocery business that was initially valued at over US\$5 billion and eventually lost hundreds of millions until it went bankrupt (Boyer et al., 2009; Ring \& Tigert, 2001). Webvan's promise of 30-min time windows proved to be a considerable logistical challenge (Boyer et al., 2009). Some of their biggest mistakes were not understanding customer expectations, poor marketing, and aiming at an unrealistically large geographic area, which proved to be too costly (Lunce, Lunce, Kawai, \& Maniam, 2006). As a result, companies need to face the trade-off between satisfying customer expectations to improve sales and the related logistic costs (Yang, Strauss, Currie, \& Eglese, 2014).

Last-mile costs have been estimated to account for between $13 \%$ and $75 \%$ of total logistic costs (Gevaers et al., 2011; Onghena, 2008). One of the most problematic issues is when delivery requires the presence of the customer. If no specific window of delivery is arranged, the failure rate is inevitably high, and additional visits may be necessary depending on the customer's response. Failed delivery rates may be reduced by allowing customers to choose the delivery time at the expense of increased logistics costs. Tight time windows require more mileage for the same number of deliveries, which is a phenomenon referred to as the 'ping-pong effect' due to the graphic visualisation of the schedule where vehicles have to revisit geographically close locations at different times to accommodate time windows (Gevaers et al., 2011).

Although in some business models, time windows are allowed in the service, e.g., online grocery delivery such as Ocado ( $1 \mathrm{~h}$ time window) and Tesco ( $2 \mathrm{~h}$ time window ${ }^{1}$ ) (Boyer et al., 2009), most home delivery services do not currently provide a time window for the delivery (Visser et al., 2014). The negative issues related to home delivery identified by customers are: i) delivery is not on time, not at home to receive the delivery, or item not delivered as specified; ii) delivery charges are too high or delivery time is too long; and iii) forced to stay at home (approximately 50\% stay at home) (Visser et al., 2014).

A number of technologies and initiatives are available to support planners in satisfying customers' expectations. With the increasing scientific interest in improving logistics operations in cities, the concept of city logistics has been defined as "the process for totally optimising the logistics and transport activities by private companies in urban areas while considering the traffic environment, the traffic congestion and energy consumption within the framework of a market economy" (Taniguchi, Thompson, Yamada, \& Van Duin, 2001). Intelligent Transport Systems (ITS) and models are crucial for the optimisation of urban freight systems (Taniguchi \& Thompson, 2002).

The importance of improving freight transport in cities is based on the fact that $85 \%$ of the EU's GDP is generated in urban areas where $72 \%$ of the European population lives (Cattaruzza, Absi, Feillet, \& GonzálezFeliu, 2015; European-Commission, 2009). Some of the special characteristics of route planning in urban areas are congestion, reliability of schedules, high customer density, accidents, regulation and access restrictions (especially in old European cities where streets are narrow with restricted parking) (Cattaruzza et al., 2015).

Computerized Vehicle Routing and Scheduling Systems (CVRS) can support dispatchers and route planners along with traffic patterns from crowdsourcing data (e.g., Google Traffic and Waze) (OR/MS-Today, 2016). However, the solution algorithms must be improved for the vehicle routing problem (VRP), especially the timedependent VRP, which consider congestion because the travel time between locations depends on the departure time (e.g., travel times at peak hours are longer compared to off-peak journeys in free flow conditions) (RinconGarcia, Waterson, \& Cherrett, 2017). Failure to account for congestion in logistics routing decisions leads to drivers of freight vehicles running out of hours, missed deliveries and additional overtime payments (Haghani \& Jung, 2005; Kok, Hans, \& Schutten, 2012).

CVRS is usually supported by metaheuristic algorithms to provide routing solutions to the industry (Drexl, 2012). However, tailoring metaheuristic algorithms for rich variants that include the restrictions present in real operations might yield poor solutions. An example is the VRP variant that addresses the driving hours regulations, which limit the driving times and working times according to the vehicle type (VOSA, 2011). After its first formal formulation by Goel (2009), which introduced benchmarking instances and a solution method

\footnotetext{
${ }^{1}$ http://www.tesco.com/groceries/help/default.aspx?rel=help\#my_delivery. Accessed on 04-09-2015.
} 
based on a large neighbourhood search (LNS) metaheuristic. The results from a different LNS tailoring proposed by Prescott-Gagnon, Desaulniers, Drexl, and Rousseau (2010) obtained highly improved results, namely, a reduced number of vehicles $(31.7 \%)$ and travel distance $(17.2 \%)$. Therefore, studying the quality of routing algorithms is important. In a test conducted by an academic group using different CVRS providers, a significant difference in the quality of solutions was found. The best and the worst schedules in instances of only 100 customers varied by up to $10 \%$, where larger differences were present in instances with more customers (Bräysy \& Hasle, 2014; Hallamaki et al., 2007).

This papers presents an algorithm that is capable of improving the state-of-the-art for a rich VRP variant that includes hard time windows, time-dependent travel times and a sub-set of the driving hours regulations. This variant is relevant for urban and regional routing to provide accurate schedules that comply with the current regulations in Europe (TDVRP-UEC) and introduces an extension to comply with The Road Transport (Working Time) Regulation 2005 in the UK (TDVRP-UEC-UW). Additionally, the algorithm is used in instances that account for city logistics conditions to provide knowledge to researchers and the industry regarding the last-mile challenge and to show the implications of using the proposed algorithm for analysing the relation between terms of service, congestion, regulation, costs and emissions.

\section{Literature review}

The first formal formulation for the routing and scheduling of vehicles was introduced by Dantzig and Ramser (1959) and is known as the VRP. Given the requests and locations of a number of customers, the VRP finds a solution that fulfils all customer demands and minimises travel distances (without exceeding vehicle capacities). After this first formulation, a number of variants that introduce additional constraints have been proposed in the literature. Variants account for conditions that are present in logistics operations such as the following: i) time windows, where customers expect delivery within a specific period of time (VRPTW) (Solomon, 1987); ii) time-dependent travel time, where the time spent travelling between locations varies according to the departure time due to congestion (TDVRP) (Figliozzi, 2012); iii) driving hours regulations that limit the amount of hours that can be driven in a day and during a continuous period (VRP-EC) (Kok, Hans, Schutten, \& Zijm, 2010).

The VRPTW has been widely studied by the scientific community, with the primary objective typically being to minimise the required number of vehicles and a secondary objective function of minimising the travel distance (Cordeau, Gendreau, Laporte, Potvin, \& Semet, 2002). However, the key objective of the logistics industry is to minimise cost rather than distance; the cost structure of a logistics operation centres around the fixed costs of the vehicles, the labour costs of the drivers, and the running cots per unit distance (Dullaert, Janssens, Sörensen, \& Vernimmen, 2002). Table 1 shows the cost structure of different vehicle types used by Dullaert et al. (2002) to exemplify the importance of understanding the transport cost structure. In this example, the time coefficient is related to delivery duty time, which is the sum of driving, breaks, waiting, loading and unloading times.

Table 1.

Structure of transportation costs in Euros

\begin{tabular}{lcc}
\hline Type of vehicle & $\begin{array}{c}\text { Hour } \\
\text { coefficient }\end{array}$ & $\begin{array}{c}\text { Kilometre } \\
\text { coefficient }\end{array}$ \\
\hline Delivery van $0.5 \mathrm{t}$ & 16.03 & 0.10 \\
Lorry 5 t & 17.14 & 0.15 \\
Lorry 8 t & 18.06 & 0.17 \\
Lorry 20 t & 20.88 & 0.21 \\
Truck and trailer & 27.75 & 0.24 \\
\hline Source: Dullaet et al (2002)
\end{tabular}

Source: Dullaert et al. (2002)

The VRP and its variants have been of interest to researchers due to the difficulty in finding optimal solutions. The variants previously mentioned are considered 'NP-Hard'; therefore, no exact algorithm has been developed to consistently provide optimal values. However, metaheuristic algorithms have been successfully developed to solve the VRP and are used to provide solutions for the logistics industry (Drexl, 2012). Algorithm development and analysis is an ongoing research area, consisting of designing new search techniques or tailoring existing ones and comparing the results for a specific variant (Cordeau et al., 2002; Gendreau, Ghiani, $\&$ Guerriero, 2015). 
Although most of the proposed variants and solution algorithms in the literature consider travel time between locations with constant speed, the TDVRP has recently received attention from researchers due to its potential for providing accurate schedules that consider time-dependent travel times caused by congestion in cities (Gendreau et al., 2015).

Analysis of schedules supported by VRP models with time-dependent travel times compared to models using constant speed illustrate the impact of not considering congestion on routing decisions when speed varies during deliveries (Kok et al., 2012). Mancini (2014) carried out a case study in Torino comparing constantspeed routing versus time-dependent routing with a GRASP metaheuristic, results show savings of $12.5 \%$ in travelling times when routing considering congestion. Similar results are presented by Mancini (2017) in theoretical instances with a hybrid algorithm, promising solutions are generated with a multistart heuristic to later be used as columns in a Set Partitioning formulation.

The solutions presented by constant-speed models have been shown to underestimate the actual travel time and to provide unrealistic solutions; furthermore, constant-speed solutions often fail to honour customer delivery times (Donati, Montemanni, Casagrande, Rizzoli, \& Gambardella, 2008; Fleischmann, Gietz, \& Gnutzmann, 2004; Ichoua, Gendreau, \& Potvin, 2003). Reported managerial solutions to account for congestion without the use of time-dependent models, such as planning vehicle schedules with average travel times, might lead to poor solutions (e.g., more vehicles, increased duty time, longer travelled distance and subsequently extra costs) compared to solutions based on the use of time-dependent VRP variants (Kok et al., 2012).

The first formal formulation of the TDVRP was introduced by Malandraki (1989) and Malandraki and Daskin (1992). The function that represented travel time variability was modified to account for the 'first-infirst-out' condition by Ichoua et al. (2003) (a vehicle with a later departure time cannot arrive before a vehicle with a prior departure time in the same link). Exact algorithms for time-dependent routing problems have been introduced. Montero, Méndez-Díaz, and Miranda-Bront (2017) proposed a Linear Programming model with a branch-and-cut scheme for the time-dependent travelling salesman problem with time windows capable to solve instances up to 40 customers. Dabia, Ropke, Van Woensel, and De Kok (2013) implemented a pricing algorithm utilising a column generation and a labelling algorithm for the time-dependent VRP with time windows (TDVRPTW) reaching optimality for only $15 \%$ of the 56 test problems with 100 customers.

Gendreau et al. (2015) conducted a literature review in time-dependent routing problems. Some of the mentioned problems are:

i) Time-dependent point-to-point route planning where the optimal path between two locations in a road network must be found. The challenge relies on providing efficient algorithms on-line for the nextgeneration web-based travel information systems that require results in milliseconds or microseconds.

ii) Time-dependent VRP variants where techniques for constant-speed classic network optimization problems exist but it is required research for their time-dependent counterparts.

iii) VRP variants that consider fuel consumption in the objective function and congestion.

Time-dependent VRP variants create new complexities for algorithm design as route evaluation is considerably more computationally expensive with time-dependent travel times. Common local search procedures for constant-speed VRP variants require significant modification as alterations within a route that occur as part of the search process could potentially affect the feasibility of the remaining route. This might alter the departure times of subsequent visits to customers and consequently modify travel times (Harwood, Mumford, \& Eglese, 2013). Figliozzi (2008) and Figliozzi (2012) introduced the first set of benchmark instances for the TDVRPTW to evaluate the quality of the proposed algorithms along with a 'ruin and recreate' search.

A much less studied group of VRP problems are those that include additional restrictions on the operation of the vehicles. Driving hours regulations are restrictions that dictate the maximum number of driving hours in a weekly planning horizon, resting periods, and maximum driving time without a break in a working day. Limiting driving time improves road safety by reducing drivers' fatigue and drowsiness (Jensen \& Dahl, 2009). Regulation (EC) 561/2006 is related to the driving and working hours of road haulage vehicles over 3.5 tons (European Union, 2006), with supplementary regulations sometimes found in particular countries. In the UK, The Road Transport (Working Time) Regulation 2005 imposes additional restrictions on drivers, such as mandatory breaks after six hours of working time even in situations where only a small portion of that time has actually been driving (VOSA, 2011).

Studies that include driving hours restrictions in VRP scheduling have usually considered long-haul operations, where many of the restrictions are focussed. For example, Goel (2009) proposed an LNS algorithm and instances for this variant. In urban delivery problems, the minimum resting periods and maximum number of driving hours per week are less constraining and are usually easier to accomplish within a schedule (especially because daily planning is typically more common in urban delivery than the longer planning horizons required for crew scheduling for long-haul operations). Kok et al. (2010) introduced instances for problems with time-dependent travel times without the long-haul restrictions to account for Regulation (EC) 561/2006. These regulations are described in this research as urban rules on driving hours (TDVRP-UEC). 
The primary objective is to minimise the required number of vehicles, and the secondary objective is to minimise either travel distance or duty time. When the sub-set of rules applied to regional or urban environments that consider only daily planning horizons, the decisions supported by the model are as follows: i) assigning customers to vehicles, ii) sequencing customer visits for each vehicle, and iii) selecting departure times for each vehicle from the depot and at each customer to account for the sub-set of rules on driving hours where breaks are assumed to be taken only at customer locations. For regulation (EC) 561/2006, the algorithm is an extension of Kok et al. (2010) that considers adding breaks in a dynamic programming (DP) heuristic. A characteristic of the algorithm is that the minimisation of duty time as a second objective substantially reduces route duration at the expense of requiring more vehicles and longer travel distances (Kok et al., 2010).

In the literature review, no other work was found addressing rules on driving hours and time-dependent travel times. A new VRP variant to account for Regulation (EC) 561/2006 in urban environments and The Road Transport (Working Time) Regulation 2005 (TDVRP-UEC-UW) is introduced in this research. The timedependent VRP with time windows and rules on driving hours is the form of the problem that is relevant to freight companies that operate in urban environments. Although operational research techniques do exist to solve rich VRP variants, it is clearly important to the industry to understand the capabilities of current algorithms and to improve them if necessary. Therefore, this research presents a definition of the variants, introduces the tailoring of an algorithm specifically designed to manage these restrictions and evaluates the performance of the proposed algorithm (in relation to both theoretical objective functions and the transport cost structure in the urban logistics industry).

\section{Problem Definition}

\subsection{The time-dependent VRP with time windows}

The TDVRPTW is defined as follows: if $n$ customers request deliveries, let $G=(V, A)$ be a graph where vertex $V=\left(v_{0}, v_{1}, \ldots, v_{n}\right)$, in which $v_{0}$ is the depot and $v_{1}, \ldots, v_{n}$ is the set of customers, and $A$ is the set of arcs between the elements of vertex $V$. An unlimited number of vehicles based on depot $v_{0}$ with a maximum capacity of $q_{\max }$ are available. Each element of $V$ has an associated demand $q_{i} \geq 0$, a service time $g_{i} \geq 0$ (notice that $0=q_{0}=g_{0}$ ), and a service time window $\left[e_{i}, l_{i}\right]$. The departure time of any given vehicle from $v_{i}$ is denoted as $b_{i}$; the arrival time is denoted as $a_{i}$. Then, for each arc $(\mathrm{i}, \mathrm{j}) \in A$, there exists a travel time $t_{i j}\left(b_{i}\right) \geq 0$, which is a function of the departure time from $v_{i}$ and the distance $d_{i j}$ (see Appendix A). The primary objective is to minimise the number of vehicles, and the secondary objective is to minimise the sum of travelled time and/or travelled distance that guarantees every customer is visited once and receives the full demand and that the arrival time is before $l_{i}$. If the arrival time is before $e_{i}$, the vehicles have to wait until $e_{i}$ (which is often called a hard window because no early or late arrivals are permitted). In addition, the vehicles must depart from and return to the depot at the end of their trip, and their maximum capacities cannot be exceeded.

\subsection{Urban rules on driving hours}

Both the TDVRP-UEC and the TDVRP-UEC-UW are extensions of the TDVRPTW; therefore, the problem description presented in section 3.1. is still applicable for these variants. The primary objective is to minimise the number of vehicles, but the secondary objective is to minimise either travel distance or duty time (route duration). Rules on driving hours that are applicable to vehicles over 3.5 tons in the UK are subject to regulation (EC) 561/2006 and The Road Transport (Working Time) Regulation 2005. Therefore, common definitions are required to introduce these constraints into the model; the following are proposed:

Route Duration: Period of time between the vehicle leaving the depot before the first request and returning to the depot after servicing the last request.

Accumulated Working Time: Accumulated time during which the driver cannot freely use his time (driving, loading or unloading, other work). This includes waiting to service a customer when the foreseeable duration is not known.

Accumulated Driving Time: Accumulated time during which the driver has been driving between valid breaks of $45 \mathrm{~min}$; see RD1.

Total Accumulated Driving Time: Accumulated time during which the driver has been driving in the working day. 
Accumulated Break EC: Accumulated break time that meets regulation (EC) 561/2006 following restriction RD1.

Accumulated Break UW: Accumulated break time that meets The Road Transport (Working Time) Regulation 2005.

The additional sets of constraints applicable for planning horizons of one day to account for the rules on driving hours are as follows:

Relaxed driving time constraints following regulation (EC) 561/2006 as proposed by Kok et al. (2010)

RD1. A period between two breaks of at least 45 min is called a driving period. The accumulated driving time in a driving period may not exceed $4.5 \mathrm{~h}$. The break that ends a driving period may be reduced to $30 \mathrm{~min}$ if an additional break of at least $15 \mathrm{~min}$ is taken anywhere during that driving period. The driving hours regulations do not allow service times at customers to be considered as break time.

$R D 2$. The total accumulated driving time may not exceed $9 \mathrm{~h}$ for any individual driver.

$R D 3$. The route duration may not exceed $13 \mathrm{~h}$ for any individual driver.

The Road Transport (Working Time) Regulation 2005 (VOSA, 2011)

RD4. Mobile workers must not work more than 6 consecutive hours without taking a break.

RD5. If the Accumulated Working Time is between 6 and $9 \mathrm{~h}$, the working time should be interrupted by a break or breaks totalling at least $30 \mathrm{~min}$.

RD6. If the Accumulated Working Time is more than $9 \mathrm{~h}$, the working time should be interrupted by a break or breaks totalling at least $45 \mathrm{~min}$.

RD7. Breaks should be last for at least $15 \mathrm{~min}$.

Constraint RD3 was proposed by Kok et al. (2010) to comply with the part of regulation EC (561/2006) that dictates that the daily rest period shall be at least 11 hours. Although the original restriction in regulation EC (561/2006) could be handled in different ways, it is considered in this research as proposed by Kok et al. (2010) in order to be able to compare results of the proposed algorithm.

An example of a valid schedule incorporating driving hours regulation (EC) 561/2006 over a single working day for one driver is shown in Figure 1. RD1 is satisfied by taking 2 breaks with a total duration of 45 min after an Accumulated Driving Time of $4.5 \mathrm{~h}$; the first break lasts for $15 \mathrm{~min}$, and the second one is $30 \mathrm{~min}$.

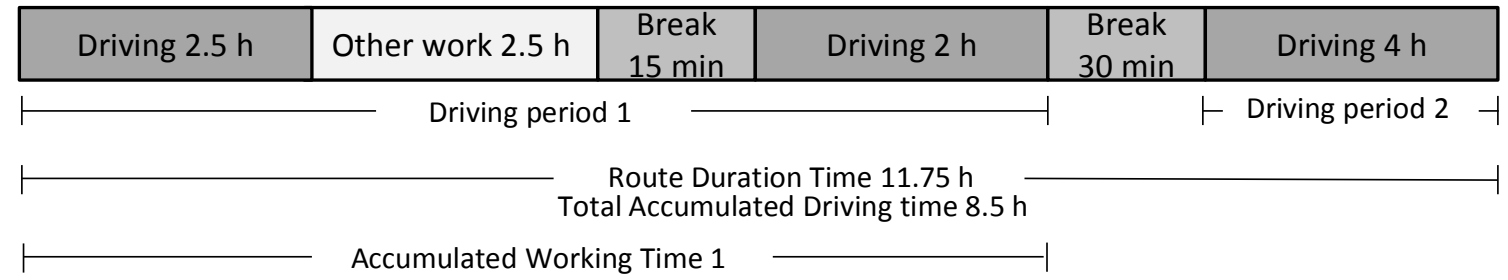

Fig. 1. Valid schedule for deliveries following regulation (EC) 561/2006.

However, the schedule presented in Figure 1 is invalid when applying The Road Transport (Working Time) Regulation 2005 because there is only a 15 min break in Accumulated Working Time 1 (7 hours). However, an Accumulated Break UW of $30 \mathrm{~min}$ is required during an Accumulated Working Time with a duration of between 6 and 9 hours (Figure 2). 


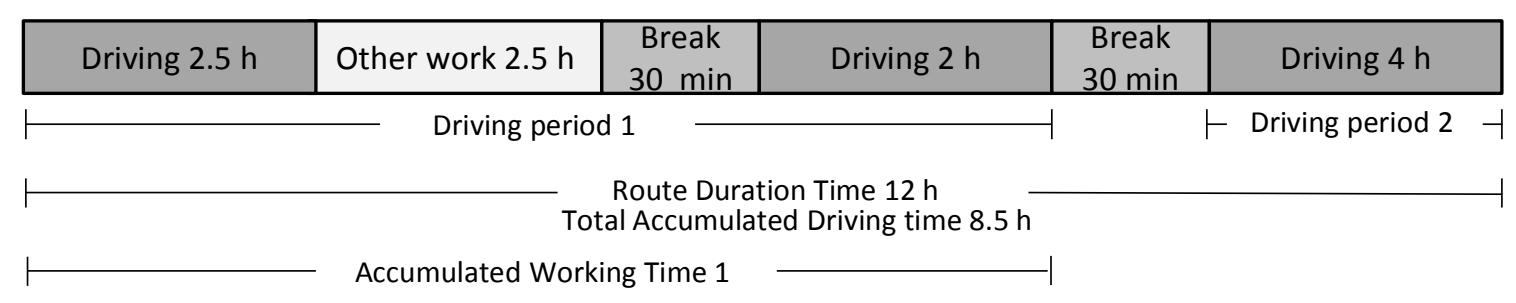

Fig. 2. Valid schedule for deliveries with regulation (EC) 561/2006 and The Road Transport (Working Time) Regulation 2005.

\section{Algorithm description}

Among the range of metaheuristic algorithms to solve VRP variants there are different elements to guarantee that different regions of the search space are visited (e.g. Tabu Search or Genetic Algorithm) in addition to neighbourhood exploration procedures. Successful implementations to provide VRP solvers for multiple variants have been proposed by: i) Vidal, Crainic, Gendreau, and Prins (2014) using a hybridization of Genetic Algorithm with classical local search procedures such as 2-OPT*, 2-OPT, CROSS and I-CROSS; and ii) Pisinger and Ropke (2007) implementing an Adaptive Large Neighbourhood Search (ALNS).

ALNS is an extension of LNS, where the procedures used to remove and reconstruct solutions in the search process are chosen from an adaptive mechanism that evaluates performance procedures and favours those that have achieved higher improvements (Ropke \& Pisinger, 2006). Heuristics based on LNS have shown outstanding results in solving a number of transportation and scheduling problems of a tightly constrained nature (such as the problem imposed by the use of time windows) (Pisinger \& Ropke, 2010). Additionally, LNS stands out in terms of simplicity and wider applicability for complex VRP variants (Vidal, Crainic, Gendreau, \& Prins, 2013).

In the specific case of the TDVRPTW, Rincon-Garcia et al. (2017) proposed an LNS implementation that improved the results provided by Figliozzi (2012) in 672 test instances, namely, it improved the number of vehicles (4.2\%), travel distance (10.9\%) and travel time (12\%).

In this research, the metaheuristic is tailored to address the rules on driving hours by implementing a 'Scheduler' algorithm based on object programming that is specifically designed to be incorporated into the LNS procedures and a diversification procedure to avoid previously explored solutions based on random elements. The proposed algorithm first constructs a feasible route, then minimises the number of vehicles in a search space that allows violations of time windows and finally minimises the second objective (distance or route duration). The LNS movements used in the proposed algorithm are the following:

Destruction procedures

- Worst-Removal: Remove the customers that have the most negative impact on the objective function.

- Random-Ruin: Randomly remove a number of customers.

- Radial-Ruin: Randomly select a customer and remove a number of the closest customers.

- Sequential-Ruin: Select a random route, select a random customer and remove a chain of consecutive customers.

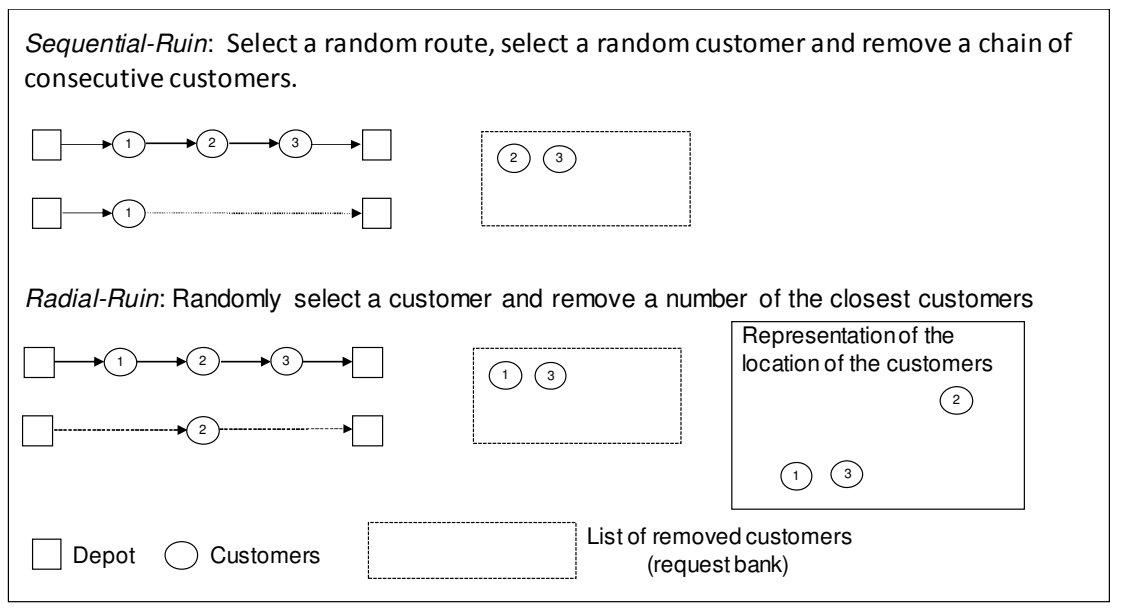


Recreation procedure

- $\quad$ Basic-Greedy Heuristic: Try to reinsert the removed customers by calculating insertion-cost $\left(v_{i}, k, p\right)$ when customer $v_{i}$ is inserted into route $k$ at position $p$, and insert $v_{i}$ with the lowest insertion$\operatorname{cost}\left(v_{i}, k, p\right)$ in the solution. Repeat the procedure until all the customer are inserted or no feasible insertion exists. After the first insertion, evaluation is only executed in the route where the previous insertion was performed.

\section{Scheduler for driving hours rules}

The purpose of the Scheduler is to determine where to insert breaks in the current LNS movement (removing or inserting customers in a solution). The Scheduler first calculates the driving time required by the movement, then calculates the Accumulated Driving Time and Accumulated Working Time, and finally establishes whether a break is required. In the case of an insertion, it starts at the customer prior to the position of the insertion and determines whether a break must be added to make the insertion. It later calculates the break requirements at the subsequent customers in the route (Figure 3). As proposed by Kok et al. (2010), breaks are only taken at customer locations.

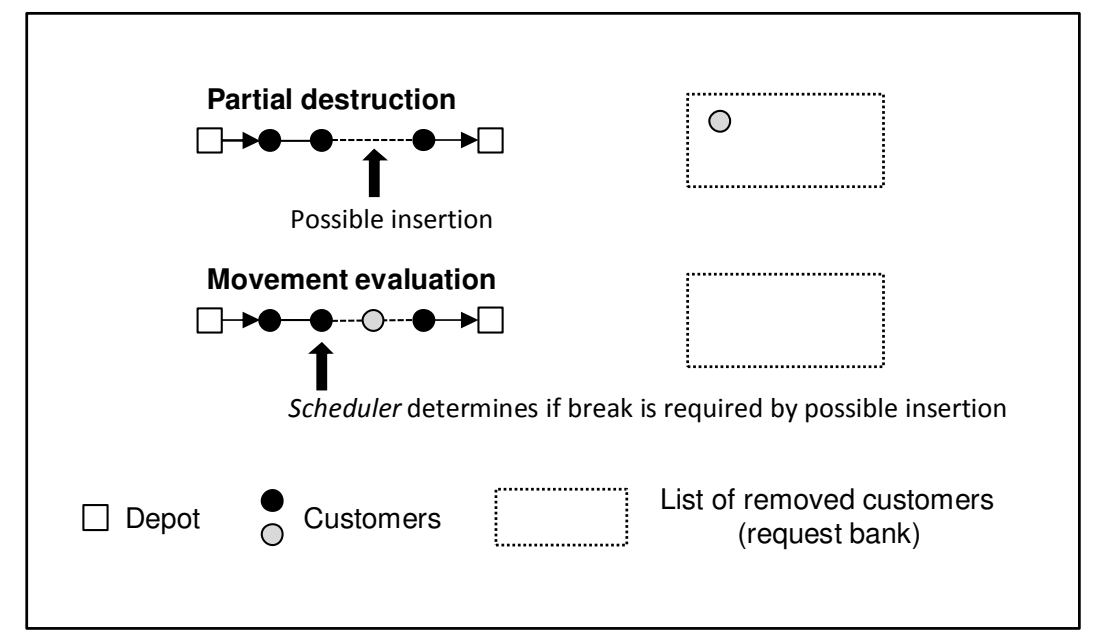

Fig. 3. Description of the evaluation performed by Scheduler to establish whether an insertion or break is required.

The time windows in the model might direct drivers to wait at a customer location when the arrival time at a customer is earlier than the lower bound of the time window. The time spent waiting for a customer might be valid as a break or part of a break; the conditions that trigger the scheduling of a break and that possibly require more time at a customer location are the following:

- $\quad$ By visiting the next customer, the Accumulated Driving Time would be over $4.5 \mathrm{~h}$ without a 45 min valid Accumulated Brake EC (Constraint RD1).

- By visiting and conducting the service at the next customer, the Accumulated Working Time would be over $6 \mathrm{~h}$ and under $9 \mathrm{~h}$, and Accumulated Break UW is under $30 \mathrm{~min}$.

- $\quad$ By visiting and conducting the service at the next customer, the Accumulated Working Time is over 9 $\mathrm{h}$, and the Accumulated Break UW is under $45 \mathrm{~min}$. 
Additionally, when the customer time windows impose a waiting time due to an early arrival, breaks taken to comply with the driving hours regulations could be taken even if no trigger is activated (not requiring additional time at the customer's location), thus taking advantage of waiting times, which is a model characteristic not implemented by Kok et al. (2010).

- If the waiting time is equal to or longer than $15 \mathrm{~min}$ and shorter than $30 \mathrm{~min}$, a break of $15 \mathrm{~min}$ is inserted that accounts for Accumulated Break UW. This break might count for Accumulated Brake EC if this variable is equal to $0 \mathrm{~min}$.

- If the waiting time is equal to or longer than $30 \mathrm{~min}$ and shorter than $45 \mathrm{~min}$, a break of $30 \mathrm{~min}$ is inserted that accounts for Accumulated Break UW. This break might count for Accumulated Break EC if the previous value of this variable is equal to $15 \mathrm{~min}$ (insertion of a $30 \mathrm{~min}$ break) or if the previous value of this variable is equal to $0 \mathrm{~min}$ (insertion of a $15 \mathrm{~min}$ break).

- If the waiting time is equal to or longer than $45 \mathrm{~min}$, a break of $45 \mathrm{~min}$ is inserted that counts for both Accumulated Break UW and Accumulated Break EC.

Note that each time that Accumulated Break EC reaches 45 min, a new driving period is inserted (Accumulated Break EC takes the value of $0 \mathrm{~min}$ ).

Note that breaks required by regulation (EC) 561/2006 also count for The Road Transport (Working Time) Regulation 2005.

The conditions for establishing whether additional time is required at a customer location to satisfy breaks according to the rules on driving hours are as follows:

- If the waiting time is longer than the required break, no extra time at the customer's location is inserted.

- If the waiting time plus the length of the time window is equal to or greater than the required break, additional time at the customer's location is inserted as the duration of the required break minus the waiting time (the break starts as soon as the vehicle arrives at the customer and service does not resume until the break is finished).

- If waiting time plus the length of the time window is shorter than the required break, service starts at the first feasible time, and the time at the customer's location is inserted as the duration of the required break (break commences after the service).

To determine break insertions and additional time at customer locations, the different characteristics of the route need to be determined. Therefore, additional return values from the Scheduler that do not impose an extra computational burden are also calculated. The returns values from the Scheduler are the following:

- Customers where breaks are scheduled

- Duration of breaks

- Duration of added time at customer

- Sum of time window violations

- Total distance

- Total travel time (driving time)

- Total waiting time

- Route duration

- Feasibility of route or penalty (violation of time windows when service starts after the upper bound of the time window)

- A random value if insertion is feasible

Different return values of the Scheduler are used according to the objective value in the optimisation stage.

The last item is used to diversify the search process of the LNS algorithm and to avoid stagnation in recreation procedures by using a random order to reinsert customers.

Note that the route duration should be under 13 hours according to RD3, therefore a route with more than 13 hours is considered infeasible. 


\section{Construction procedure}

The proposed construction procedure uses random elements to generate different solutions that have the characteristic of being feasible; this procedure is presented as follows.

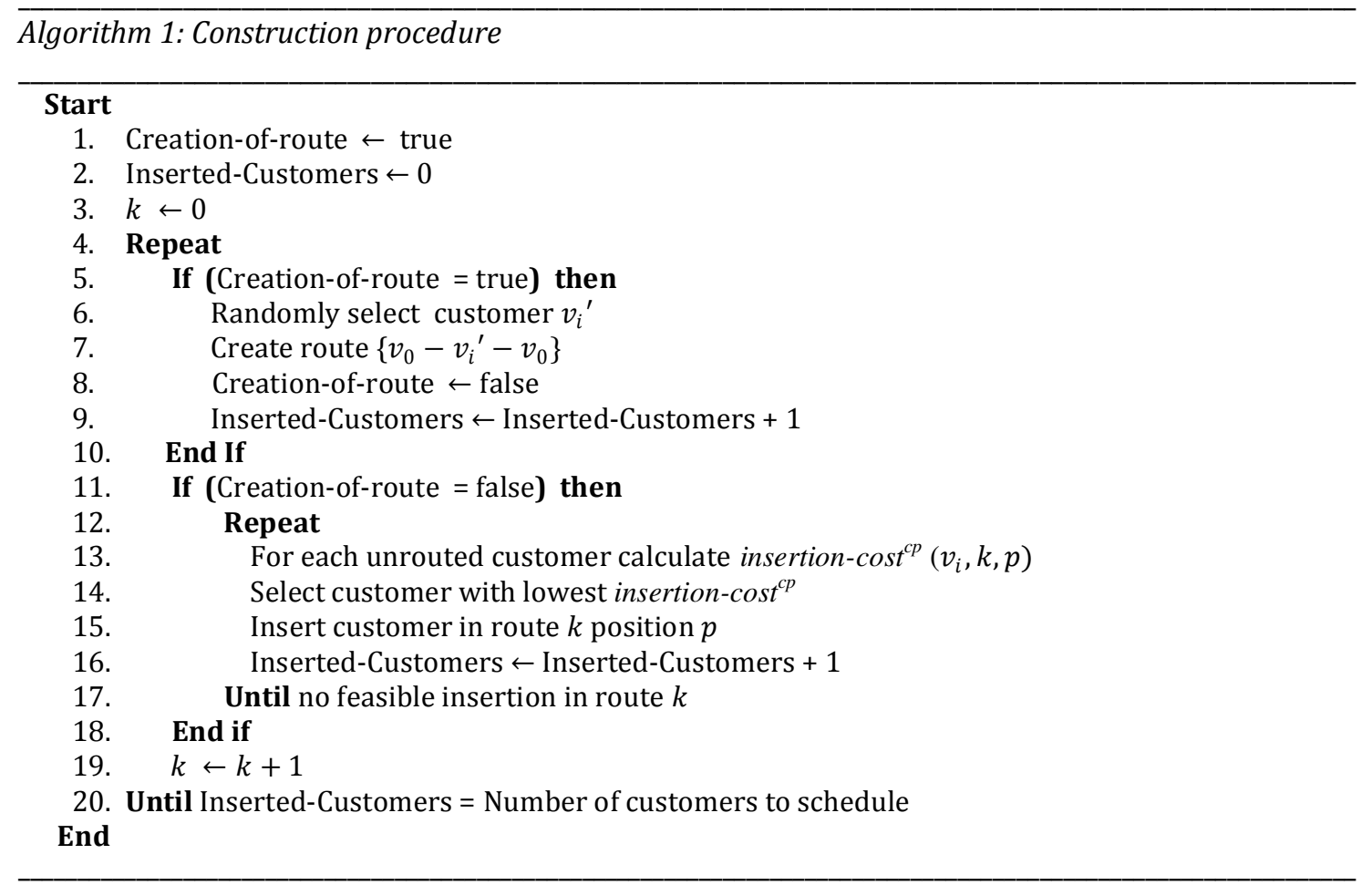

The insertion- $\cos t^{c p}$ (line 14) is the following function:

$$
\text { insertion-cost }{ }^{c p}\left(v_{i}, k, p\right)=\delta_{1}^{c p} \Delta \text { Total Travel Time }+\delta_{2}^{c p} \Delta \text { Total Waiting Time }
$$

where $\Delta$ Total Travel Time is the change in the total travel time due to inserting customer $v_{i}$ in route $k$ at position $p, \Delta$ Total Waiting Time is the change in the total waiting time due to inserting customer $v_{i}$ in route 
$k$ at position $p$, and $\delta_{1}^{c p}$ and $\delta_{2}^{c p}$ are parameters that weight the impact of travel time and waiting time, respectively, in which $\delta_{1}^{c p}+\delta_{2}^{c p^{2}}=1 ; \delta_{1}^{c p}$ and $\delta_{2}^{c p}$ might vary randomly.

This procedure can be repeated a number of times where the solution with the minimum number of vehicles is chosen as the initial solution for minimising the number of vehicles.

\section{Minimisation of the number of vehicles procedure}

In this procedure, the route (vehicle) with the minimum number of customers is removed, and customers are reinserted in the solution creating violations of the upper limit of the time windows. This procedure reduces the penalties by using LNS movements trying to reach a penalty of 0 , which implies a feasible solution with one fewer vehicle, and it is presented as follows:

Algorithm 2: Minimisation of the number of vehicles procedure

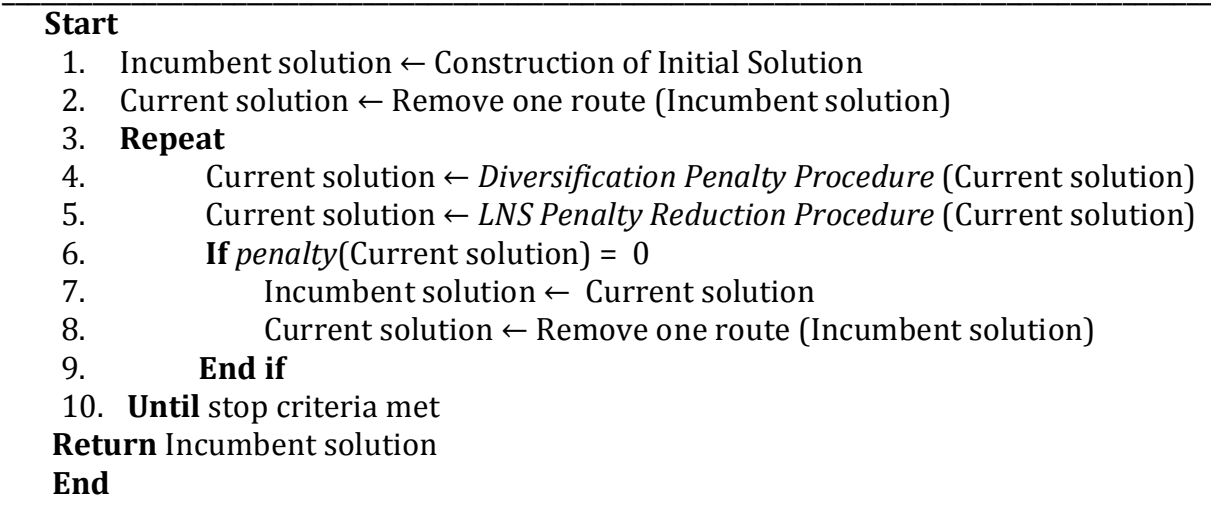

The main steps of the Minimisation of the number of vehicles procedure are the following:

i) The LNS Penalty Reduction Procedure (line 5) uses ruin procedures (Random-Ruin, Radial-Ruin, WorstRemoval, ) and the Basic-Greedy Heuristic with the following insertion-cost ${ }^{c p}$ :

$$
\text { insertion- } \operatorname{cost}^{c p}\left(v_{i}, k, p\right)=\Delta \text { Penalty }
$$

Alternatively, if there is no penalty in the insertion (to avoid stagnation), two insertion-

$\operatorname{cost}^{c p}$ values might be used:

$$
\begin{aligned}
& \text { insertion-cost }{ }^{c p}\left(v_{i}, k, p\right)=\Delta \text { travel time }+\Delta \text { waiting time } \\
& \text { or }
\end{aligned}
$$

$$
\text { insertion- } \operatorname{cost}^{c p}\left(v_{i}, k, p\right)=\text { random value }
$$

where customers that generate a penalty are first inserted and then customers that do not generate a penalty are inserted. 
ii) The Diversification Penalty Procedure (line 4) is based on selecting a random number of customers that generate a penalty (Worst-Removal) along with Random-Ruin. Then, these customers are inserted in a different route (vehicle) in the solution using the Basic-Greedy Heuristic with the previously mentioned insertion-cost ${ }^{c p}$.

\section{Minimising the second objective}

This procedure can minimise the travel distance or route duration by using LNS movements. The search strategy at the master level is a simple tabu search that prevents the search from exploring previously visited regions.

Algorithm 3: Minimisation of the travel distance/route duration procedure

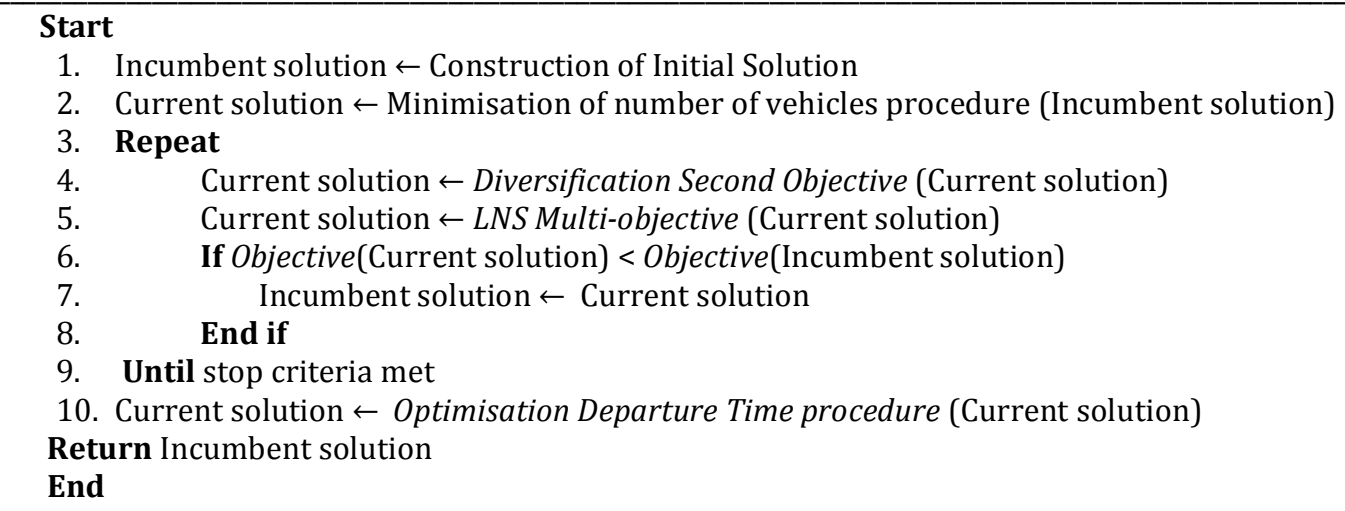

The main steps of the Minimisation of the travel distance/route duration procedure are the following:

i) LNS Multi-Objective (line 5) uses ruin procedures (Random-Ruin, Radial-Ruin and Sequential-Ruin) and the Basic-Greedy Heuristic for recreation, where insertion-cost ${ }^{\text {trp }}$ uses different returns values of the Scheduler to avoid stagnation.

insertion-cost ${ }^{\text {trp }}=\delta_{1}^{\text {trp }} \Delta$ Total Travel Time $+\delta_{2}^{\text {trp }} \Delta$ Total Waiting Time $+\delta_{3}^{\text {trp }} \Delta$ Total Distance

where

$$
\delta_{1}^{t r p}+\delta_{2}^{t r p}+\delta_{3}^{t r p}=1 ; \delta_{1}^{t r p}, \delta_{2}^{t r p} \text { and } \delta_{3}^{t r p} \text { might vary randomly }
$$

or

insertion-cost $^{\text {trp }}=\Delta$ Route duration 
ii) The Diversification Second Objective procedure (line 4) is based on removing two sequences of customers of random length, calling Sequential-Ruin, and inserting these customers in the solution using Basic-Greedy Heuristic with the insertion-cost ${ }^{\text {trp }}$ set as a random number when insertion is feasible. A tabu search maintains records of the explored solutions to force the search to new regions; the recorded tabu solution characteristic is the value of the objective function.

Taking route minimisation as the secondary objective, the evaluation to store an improved solution (line 6) uses the Optimisation Departure Time procedure to obtain the minimum possible route duration of the current solution.

The Optimisation Departure Time procedure is an algorithm that iteratively moves the departure time from the depot forward in an iterative way until the route becomes unfeasible and modifies the route if it finds a departure time that reduces the route duration.

Although the proposed tailoring can minimise travel distance or route duration, an optimisation of departure time is always executed to minimise route duration when the search is terminated (line 10). In the case of minimising travel distance, the procedure does not affect the obtained distance and provides solutions with compact routing times.

\section{Theoretical test instances}

The well-known test instances for the VRPTW proposed by Solomon (1987) consist of 56 problems of 100 customers. Figliozzi (2008) modified these by adding speed profiles to account for traffic congestion (S1). The depot opening time $\left[e_{o}, l_{o}\right]$ is divided into 5 periods of equal duration with 3 speed profiles (TD1-TD3). An additional profile (TD0) with a constant speed of 1 is also considered for comparison to the best-known values with constant speed models. The speed profiles are as follows:

$$
\begin{aligned}
\text { TD0 } & =[1.00,1.00,1.00,1.00,1.00] \\
\text { TD1 } & =[1.00,1.60,1.05,1.60,1.00] \\
\text { TD2 } & =[1.00,2.00,1.50,2.00,1.00] \\
\text { TD3 } & =[1.00,2.50,1.75,2.50,1.00]
\end{aligned}
$$

The test instances proposed by Solomon present different depot opening times where units of distance and time are equal. For ease of comparison, Kok et al. (2010) introduced an additional modification in which the breaks required by regulation (EC) 561/2006 are scaled to a working day of 12 hours (from 7 AM until 7 PM) based on the different opening times of the depot in the Solomon instances (the length of the break and the maximum Accumulated Driving Time without a break are scaled). These scaled instances with the Figliozzi (2008) speed profiles collectively provide $(56 \times 4=) 224$ test instances that are used as the basis of the results in this research.

An additional set of instances (S2) are proposed by Kok et al. (2010) in order to represent a working day of 16 hours in which constraint $R D 3$ have to be considered, the opening time of the depot is advanced by 2 hours and the closure time is extended by 2 hours. A selection of time windows of customers is adjusted, if the opening time of the time window of the customer equals the opening time of the depot in the original instances, opening time window at customer is adjusted accordingly; the end of the time window is also adjusted for customers where vehicles can depart at the end of the time window and still arrive at the closing time of the depot in the original instances, and adjusted accordingly with the new closing time of the depot. Speed profiles for S2 are as follows: 


\section{Experimental results from theoretical instances}

The proposed LNS algorithm is not adaptive, therefore parameters $\delta_{i}$ are set to vary randomly and destruction procedures in each of the proposed algorithms are set to be executed an equal number of times. In algorithm 2 , the LNS Penalty Reduction Procedure uses the insertion-cost ${ }^{c p}\left(v_{i}, k, p\right)=$ random value only when the ruin procedure is Sequential-Ruin in order to force the insertion to new regions of the search space, insertion$\operatorname{cost}^{c p}\left(v_{i}, k, p\right)=\Delta$ travel time $+\Delta$ waiting time is used when other destruction procedures are invoked. In algorithm 3 , ruin procedures and insertion costs are set to be invoked an equal number of times, each ruin procedure is used with each insertion procedure. Termination criteria was set to a total execution time of 2 minutes for the sum of the 3 algorithms.

Kok et al. (2010) provide solutions for the TDVRP-UEC where no early or split breaks are considered, which will be noted as TDVRP-UEC*. In this research, the 'Scheduler' algorithm is set to accommodate the TDVRPUEC* constraints along with constraints that allow the consideration of 15 minutes early breaks and split breaks when time windows at customers impose waiting time due to an early arrival, which will be noted as TDVRPUEC, note that TDVRP-UEC takes into consideration the actual regulation (EC) 561/2006 for daily routing and not a relaxed set of constraints. The DP algorithm that solves the TDVRP-UEC* is noted as DP*, the LNS algorithm that solves the TDVRP-UEC* is noted as LNS*, and the LNS algorithm that solves the TDVRP-UEC noted as LNS. Additionally, results for the TDVRP-UEC-UW considering early and split breaks are shown.

Table 2.

Impact of the rules on driving hours with no congestion (TD0) and minimising travel distance as the secondary objective (100 customers), instances S1 for a 12 hours working day.

\begin{tabular}{|c|c|c|c|c|c|c|}
\hline \multicolumn{3}{|c|}{ VRP variant and algorithm } & \multirow{2}{*}{$\frac{\text { NV }}{405}$} & $\underline{\Delta}$ & \multirow{2}{*}{$\begin{array}{c}\text { Distance } \\
57187\end{array}$} & \multirow[t]{2}{*}{$\Delta$} \\
\hline VRPTW & & (1) & & & & \\
\hline TDVRP-UEC** & $\mathrm{DP}^{*}$ & (2) & 514 & $26.9 \%$ & 72464 & $26.7 \%$ \\
\hline TDVRP-UEC** & LNS* & (3) & 446 & $10.1 \%$ & 61480 & $7.5 \%$ \\
\hline TDVRP-UEC & LNS & (4) & 433 & $6.9 \%$ & 59862 & $4.7 \%$ \\
\hline TDVRP-UEC-UW & LNS & (5) & 452 & $11.6 \%$ & 60995 & $6.7 \%$ \\
\hline
\end{tabular}

(1) Best-known values, see Vidal et al. (2013) (2) Kok et al. (2010); running time of 138 min (Core 2 Quad 2.88 GHz, 4 GB RAM) (3-4) running Time of 112 min (Core i7 3.4 GHz, 16 GB RAM)

Table 3.

Results for regulation (EC) 561/2006 on driving hours in urban or regional environments and different levels of congestion with minimising the route duration as the second objective, instances S1 for a 12 hours working day.

\begin{tabular}{|c|c|c|c|c|c|c|c|c|c|}
\hline & \multicolumn{3}{|c|}{$\mathrm{DP} *(1)$} & \multicolumn{3}{|c|}{$\mathrm{LNS}^{*}(2)$} & \multicolumn{3}{|c|}{ LNS(2) } \\
\hline $\begin{array}{l}\text { Speed } \\
\text { profile }\end{array}$ & NV & Distance & $\begin{array}{c}\text { Route } \\
\text { Duration }\end{array}$ & NV & Distance & $\begin{array}{c}\text { Route } \\
\text { Duration }\end{array}$ & $\mathbf{N V}$ & Distance & $\begin{array}{c}\text { Route } \\
\text { Duration }\end{array}$ \\
\hline TD0 & 523 & 73584 & 272160 & 447 & 64780 & 263066 & 433 & 60183 & 259603 \\
\hline TD1 & 494 & 73808 & 254240 & 414 & 64756 & 247759 & 401 & 60461 & 236927 \\
\hline TD2 & 458 & 74256 & 243712 & 384 & 65069 & 237819 & 374 & 61200 & 235946 \\
\hline TD3 & 458 & 74480 & 236768 & 368 & 63848 & 233169 & 358 & 61826 & 230304 \\
\hline & 1933 & 296128 & 1006880 & 1613 & 258453 & 981813 & 1933 & 296128 & 1006880 \\
\hline$\Delta$ & & & & $16.5 \%$ & $12.72 \%$ & $2.48 \%$ & $19.0 \%$ & $17.7 \%$ & $4.4 \%$ \\
\hline
\end{tabular}

(1) Kok et al. (2010); running time of 1138 min (Core 2 Quad $2.88 \mathrm{GHz}, 4$ GB RAM)

(2) Running time of 448 min (Core i7 $3.4 \mathrm{GHz}, 16 \mathrm{~GB}$ RAM)

Table 4.

Results for regulation (EC) 561/2006 on driving hours in urban or regional environments and different levels of congestion with minimising the route duration as the second objective, instances $\mathrm{S} 2$ for a 16 hours working day.

\begin{tabular}{lll}
\hline $\operatorname{DP}^{*}(1)$ & $\operatorname{LNS}^{*}(2)$ & $\operatorname{LNS}(2)$ \\
\hline
\end{tabular}




\begin{tabular}{cccccccccc}
\hline $\begin{array}{c}\text { Speed } \\
\text { profile }\end{array}$ & NV & Distance & $\begin{array}{c}\text { Route } \\
\text { Duration }\end{array}$ & NV & Distance & $\begin{array}{c}\text { Route } \\
\text { Duration }\end{array}$ & NV & Distance & $\begin{array}{c}\text { Route } \\
\text { Duration }\end{array}$ \\
TD0 & 504 & 75040 & 274512 & 443 & 61499 & 264557 & 437 & 60664 & 261729 \\
TD1 & 474 & 76664 & 256200 & 413 & 64757 & 249032 & 405 & 62255 & 248195 \\
TD2 & 454 & 76720 & 244104 & 380 & 61947 & 237901 & 374 & 61556 & 238322 \\
TD3 & 436 & 78064 & 238616 & 362 & 63895 & 233113 & 360 & 62703 & 232554 \\
& 1873 & 306488 & 1013432 & 1598 & 252097 & 984603 & 1576 & 247178 & 980800 \\
\hline$\Delta$ & & & $14.7 \%$ & $17.7 \%$ & $2.8 \%$ & $15.6 \%$ & $19.3 \%$ & $3.2 \%$ \\
\hline
\end{tabular}

(1) Kok et al. (2010); running time of 1138 min (Core 2 Quad $2.88 \mathrm{GHz}, 4$ GB RAM)

(2) Running time of $448 \mathrm{~min}$ (Core i7 $3.4 \mathrm{GHz}, 16 \mathrm{~GB}$ RAM)

\section{Analysis of experimental results from theoretical instances}

The LNS algorithm proposed in this research outperformed the DP algorithm proposed by Kok et al. (2010) in all the test instances, the DP algorithm makes use of a giant-tour representation with a Dynamic Programming algorithm where states account for the constraints that represent the TDVRP-UEC such as capacity of the vehicle, time windows, etc. In order to consider driving time constraints (introduction of breaks and modification of the starting time of the route), a vehicle departing optimization heuristic (HVDO) without unforced waiting time and early breaks is proposed by Kok et al. (2010), note that a heuristic method was used due to the computational burden of using a more sophisticated method. Kok et al. (2010) compared the HVDO with a vehicle departing optimization ILP method (EVDO) which included unforced waiting time and early breaks, finding that the optimality GAP of HVDO is smaller than $0.5 \%$.

Dynamic Programming has been tested to solve the VRPTW, Gromicho, van Hoorn, Kok, and Schutten (2012) tested an implementation with 6 of the 56 Solomon's instances for 100 customers, obtaining solutions with 1.7 more vehicles and $11.0 \%$ more distance. The TDVRP-UEC is a generalization of the VRPTW and the TDVRPTW, and therefore the need of testing an approach that has been proven to reach best-known values for the VRPTW and improve best-known values for the TDVRPTW, such as the case of LNS metaheuristic (Gromicho et al., 2012; Rincon-Garcia et al., 2017) to provide routing solutions that comply with the driving hours regulations. In this research, LNS movements always produce solutions that comply with the European regulations on driving and working hours due to the use of the proposed Scheduler algorithm.

Results for the VRPTW could be set as lower bound for the TDVRP-UEC in instances without timedependent travel time (TD0 and TD0'). Therefore, analysis of solution accuracy for different algorithms with their respective problem formulation could be performed. While the DP* algorithm produces solutions with $26.9 \%$ more vehicles and $26.77 \%$ more distance than best-known solutions for the VRPTW; LNS* produces solutions with only $10.1 \%$ more vehicles and $7.5 \%$ more distance; and LNS $6.9 \%$ more vehicles and $4.7 \%$ more distance, see table 2. This indicates that the LNS algorithm not only provides better solutions due to implementing a formulation that considers early and split breaks but it also provides a better exploration of the search space.

The LNS algorithm also provided better results than the DP algorithm for instances S1 and S2 with formulation TDVRP-UEC*, providing even better results with formulation TDVRP-UEC, reaching up to $19.0 \%$ less number of vehicles, $17.7 \%$ less distance and $4.4 \%$ less duty time for instances S1, see table 3. LNS also proved to consistently improve results in the case where depot opening hours are extended to 16 hours where constraint RD3 might be active, providing solutions with $15.6 \%$ less number of vehicles, $19.3 \%$ less distance and $3.2 \%$ less duty time, see table 4 .

\section{Instances that represents home delivery conditions}

This section presents the impacts of regulation, the length of the time window, traffic congestion and customer density in a logistics operation for multi-drop deliveries, which represent the home delivery conditions in urban environments. Therefore, an experiment is designed in which these factors are modified, and the impacts on costs and emissions are studied. The distances between the nodes are represented as the Cartesian distances between the points to easily evaluate the impact of any variation in the factors.

The length of the service time is set at 6 min based on the case of Sainsbury's home delivery operation (Commercial-Vehicle-Engineer, 2012); the length of the time window varies between no time window to a tight time window of 1 hour; and the depot open hours are from 9 a.m. to 7 p.m. Different levels of congestion are introduced in the analysis. The average US pattern of congestion in urban environments according to the time of day is presented in Figure 4. Congestion typically has two peaks, in the morning and in the evening. TomTom (2015) has introduced a congestion level traffic index (see Table 6 for the level of congestion in selected cities). The congestion level of cities is measured by the calculated increase in overall travel times compared to a freeflow situation. For example, a congestion level of $20 \%$ corresponds to $20 \%$ longer travel times compared to 
free-flow conditions. The indicator weights the number of measurements; therefore, busier and more important roads have more influence than quieter roads.

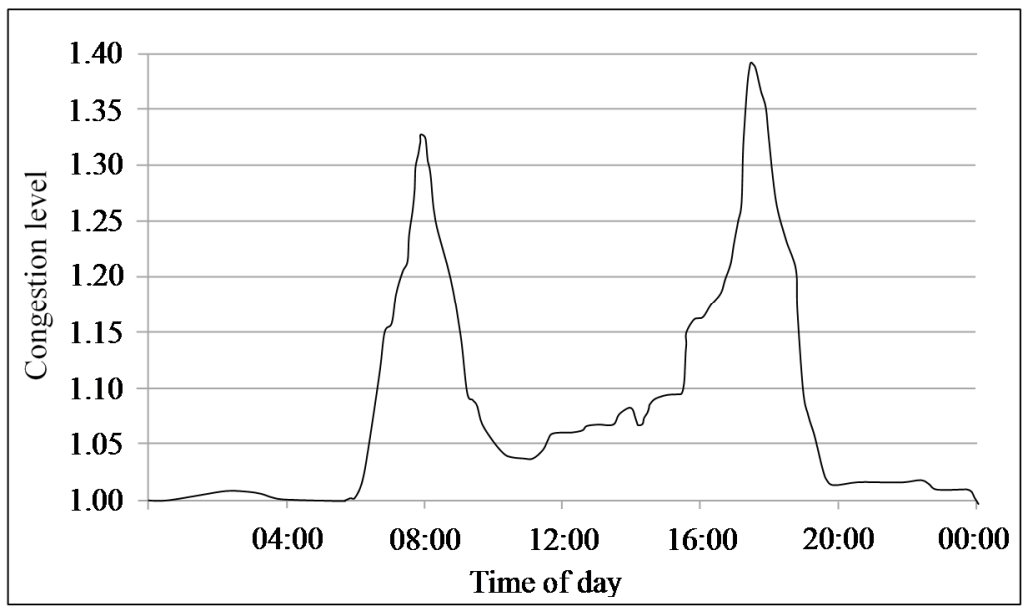

Source: US Department of Transportation (2004)

Fig. 4. Variation in the level of congestion in US cities by time of day.

Table 6.

TomTom traffic index for selected cities.

\begin{tabular}{ccccc}
\hline \multirow{2}{*}{ World rank } & City & $\begin{array}{c}\text { Congestion } \\
\text { level }\end{array}$ & $\begin{array}{c}\text { Morning peak Evening Peak } \\
(1)\end{array}$ \\
\hline 1 & Istanbul (Turkey) & $58 \%$ & $76 \%$ & $109 \%$ \\
10 & Los Angeles (US) & $39 \%$ & $60 \%$ & $80 \%$ \\
16 & London (UK) & $37 \%$ & $65 \%$ & $67 \%$ \\
90 & Birmingham (UK) & $24 \%$ & $46 \%$ & $50 \%$ \\
- & Southampton (UK) & $24 \%$ & $56 \%$ & $51 \%$ \\
\hline
\end{tabular}

(1) The busiest one-hour-long period in the morning

(2) The busiest one-hour-long period in the evening

Source: TomTom (2015)

Congestion is introduced in the scenarios following the same pattern presented in Figure 4. The four congestion levels are as follows: i) (S0) no congestion (constant speed of $48 \mathrm{~km} / \mathrm{h}$ ); ii) (S1) the evening peak speed is reduced by a factor of 1.4 compared to a free-flow state (a very similar pattern to that presented in Figure 4.); iii) (S2) the evening peak speed is reduced by a factor of 1.7 compared to the free-flow state, and the rest of the speeds in each 15 min interval are scaled accordingly, iv) (S3) the evening-peak speed is reduced by a factor of 2.0 compared to the free-flow state, and the rest of the speeds are scaled accordingly. The conditions in $\mathbf{S 3}$ are similar to those in Turkey; see Figure 5. Free-flow conditions are not present during the analysed period (9:00 AM to 7:00 PM) 


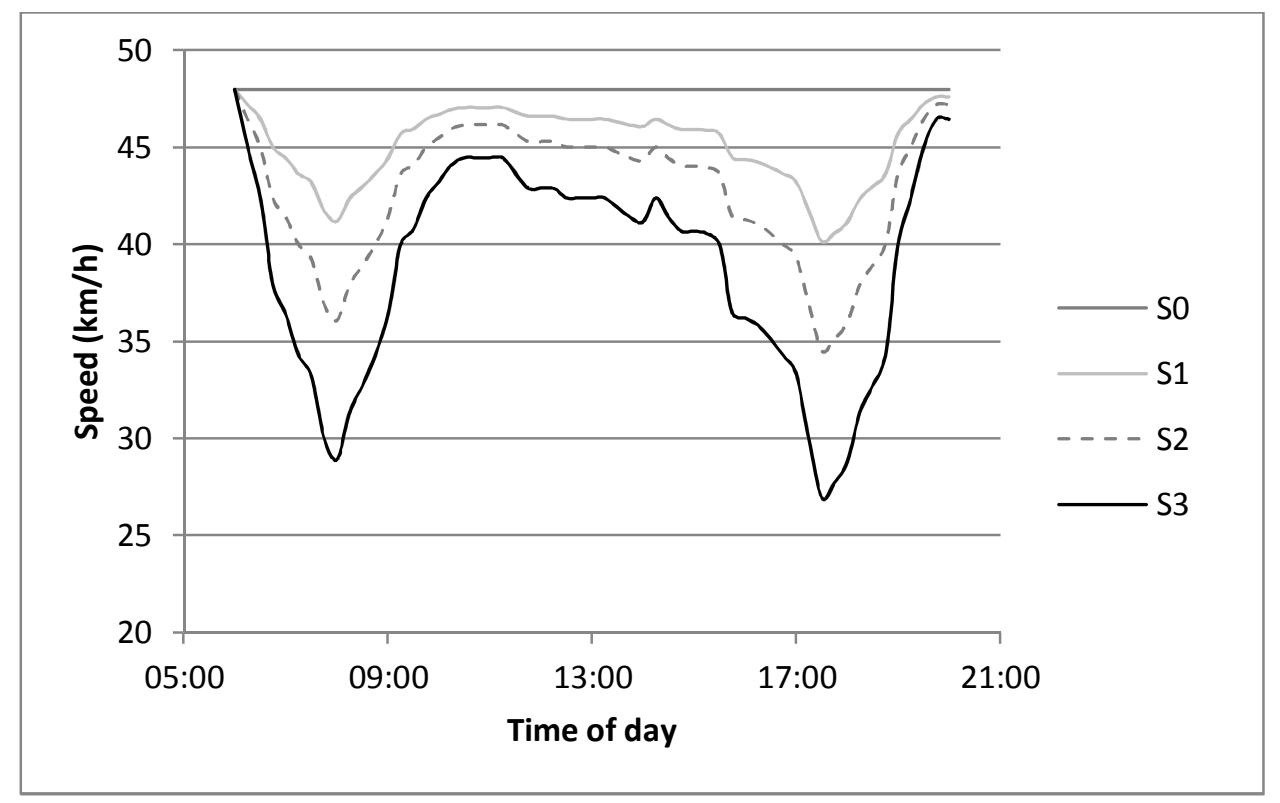

Fig. 5. Speeds according to congestion level.

The proposed scenarios are based on a densely populated area of the UK with a size of $400 \mathrm{~km}^{2}$ (the distance between the depot and the farthest customer is $10 \mathrm{~km}$ ) and include 100 or 400 customers. The customer locations follow the patterns introduced by Solomon (1987) for 100 customers and were extended to 400 customers by Gehring and Homberger (1999); the pattern is random, cluster and random-cluster. The coordinates are scaled to an area of $400 \mathrm{~km}^{2}$. Figure 6 shows the customer locations in the different scenarios. In the real world, many roads can be more quickly traversed at some times of day than at others, and the algorithm is capable of considering this data (e.g., obtaining data from Google traffic). In the proposed instances, the congestion varies uniformly in all the links of the instances according to the four congestion levels presented in Figure 5. The parameters are set for a 3.5 ton diesel van with the following cost coefficients (estimations based on FTA (2014)): a fixed cost per vehicle per day of $£ 12.51$, a coefficient per km of $£ 0.17$ and a coefficient per hour of $£ 9.91$. The fuel consumption is estimated according to the model provided by the UK Department of Transport (DFT, 2014), as shown in Figure 7, and the emissions are determined according to CarbonTrust (1 litre of diesel $=2.6676 \mathrm{kgCO}_{2} \mathrm{e}$ ). 


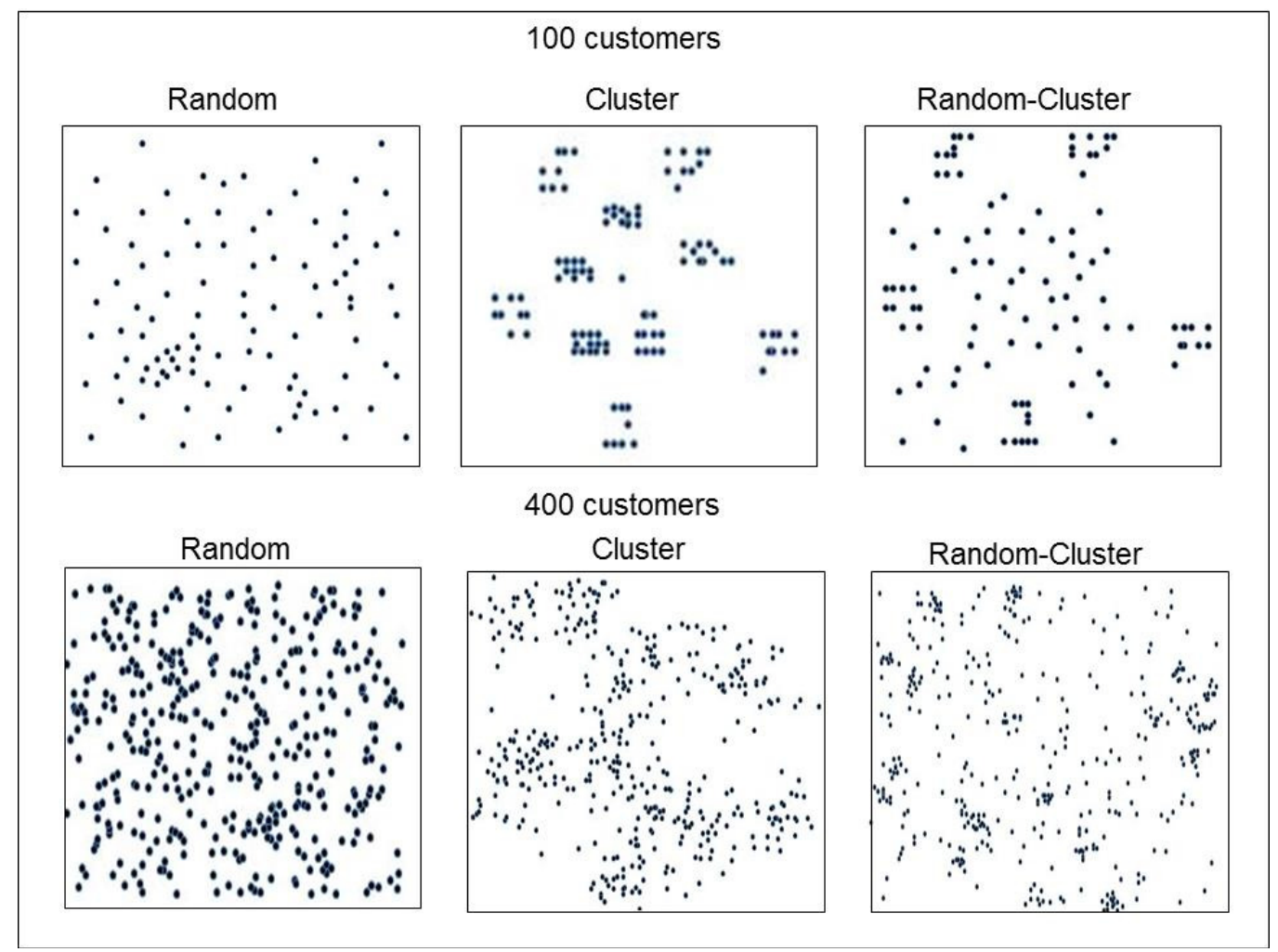

Fig. 6. Six scenarios of customer locations (area: $400 \mathrm{~km}^{2}$ ).

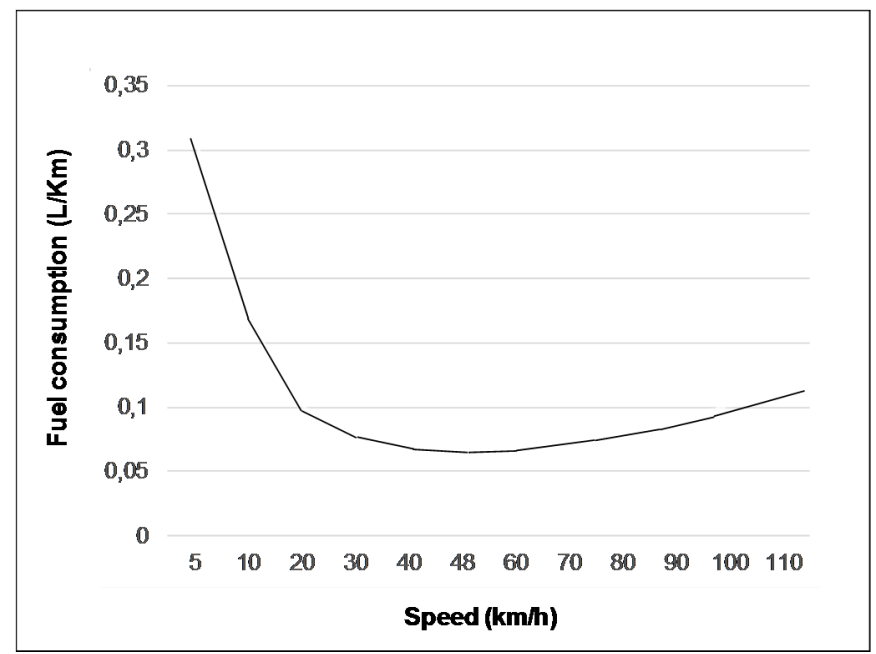

Fig. 7. Typical fuel consumption for a Diesel LGV vs. average speed with constant weight. Source: DFT (2014)

\section{Experimental results in instances that represents home delivery conditions}

The instances were executed in a Corei7 computer with 16 GB RAM in a single thread; the primary objective was minimising the number of vehicles, and the secondary objective was minimising the total cost instead of minimising the route duration. The execution time for the instances with 100 customers was set to 2 min, and that for 400 customers was set to $5 \mathrm{~min}$.

Impacts of the length of time windows and customer density

The routing results from executing three instances (cluster, cluster-random, and random) with 100 customers and 400 customers for different lengths of time windows are shown in Table 7. Tight time windows are more 
expensive and present a considerable environmental impact (up to $74 \%$ higher cost and $196 \%$ more emissions for a $1 \mathrm{~h}$ time window compared to no time window in instances of 100 customers). However, the impacts on costs and emissions can be reduced with higher density (as shown in the instances with 400 customers). The studied instances show the importance of service promises in logistic operations and economies of scale. Average distribution cost per delivery offering 1 hour time window for 100 customers is $£ 2.9$, whereas average cost decreases to $£ 1.4$ when offering no time window for 400 customers. Additionally, environmental impact increases more than 4 times in these logistics configurations.

Table 7.

Analysis of delivery costs with different lengths of time windows and customer densities for a diesel van at a constant speed of $48 \mathrm{~km} / \mathrm{h}$ (no regulations)

\begin{tabular}{|c|c|c|c|c|c|c|c|}
\hline & No Time Window & $\mathrm{AM} \mathrm{O}$ & $\begin{array}{r}\mathrm{PM} \\
\Delta \\
\end{array}$ & 2 Hour Tin & $\begin{array}{c}\text { e Window } \\
\Delta\end{array}$ & 1 Hour Tin & $\begin{array}{l}\text { e Window } \\
\Delta\end{array}$ \\
\hline \multicolumn{8}{|l|}{3 Instances of 100 customers } \\
\hline NV & 6 & 6 & & 6 & & 9 & \\
\hline Total Route Duration (Hr) & 37.1 & 40.7 & & 49.2 & & 59.6 & \\
\hline Total Distance (Km) & 341.3 & 487.8 & & 759.5 & & 1012.7 & \\
\hline Total $\mathrm{KgCO}_{2} \mathrm{e}$ & 63.0 & 90.1 & & 140.2 & & 187.0 & \\
\hline Total Cost $(£)$ & 500.8 & 561.4 & & 691.8 & & 875.4 & \\
\hline $\mathrm{KgCO}_{2} \mathrm{e}$ per delivery & 0.2 & 0.3 & $42.9 \%$ & 0.5 & $122.5 \%$ & 0.6 & $196.7 \%$ \\
\hline Cost per delivery $(\mathfrak{f})$ & 1.7 & 1.9 & $12.1 \%$ & 2.3 & $38.1 \%$ & 2.9 & $74.8 \%$ \\
\hline \multicolumn{8}{|l|}{3 Instances of 400 customers } \\
\hline NV & 15.0 & 15.0 & & 18.0 & & 22.0 & \\
\hline Total Route Duration (Hr) & 135.5 & 139.0 & & 160.0 & & 193.3 & \\
\hline Total Distance $(\mathrm{Km})$ & 743.8 & 910.4 & & 1723.0 & & 2313.0 & \\
\hline Total $\mathrm{KgCO}_{2} \mathrm{e}$ & 137.3 & 168.1 & & 318.2 & & 427.1 & \\
\hline Total Cost $(\mathfrak{f})$ & 1657.0 & 1720.0 & & 2103.8 & & 2584.1 & \\
\hline $\mathrm{KgCO}_{2} \mathrm{e}$ per delivery & 0.1 & 0.1 & $22.4 \%$ & 0.3 & $131.6 \%$ & 0.4 & $211.0 \%$ \\
\hline Cost per delivery $(\mathfrak{f})$ & 1.4 & 1.4 & $3.8 \%$ & 1.8 & $27.0 \%$ & 2.2 & $56.0 \%$ \\
\hline
\end{tabular}

Impacts of congestion and rules on driving hours

The total costs and performance indicators for delivering in the six test instances with different levels of congestion and sets of regulations are shown in Table 8. As expected, higher congestion levels increase the costs and fuel consumption (emissions) regardless of regulation (up to $9 \%$ higher cost at congestion level S3 in UECRegulation and up to $6.3 \%$ higher emissions for no regulation). Enforcing the full set of regulations in the UK increases the cost by an average of $5.7 \%$ at different levels of congestion.

Table 8.

Delivery costs with different levels of congestion and regulations for a diesel van (3.5 ton)

\begin{tabular}{|c|c|c|c|c|c|c|c|c|c|}
\hline & & $\mathbf{N V}$ & $\begin{array}{c}\text { Route } \\
\text { Duration } \\
\text { (Hr) }\end{array}$ & $\begin{array}{l}\text { Travel } \\
\text { Time } \\
\text { (Hr) }\end{array}$ & $\begin{array}{c}\text { Distance } \\
(\mathrm{Km})\end{array}$ & $\mathrm{KgCO}_{2} \mathrm{e}$ & $\Delta$ & $\begin{array}{c}\text { Delivery } \\
\text { Cost } \\
\text { (f) }\end{array}$ & $\Delta$ \\
\hline \multirow{5}{*}{ そ。 } & S0 & 97 & 814.2 & 172.7 & 8291.6 & 1531.0 & & 10692.3 & \\
\hline & S1 & 97 & 829.2 & 191.6 & 8663.3 & 1609.9 & $5.1 \%$ & 10904.1 & $2.0 \%$ \\
\hline & S2 & 99 & 838.8 & 198.5 & 8495.6 & 1593.8 & $4.1 \%$ & 10995.8 & $2.8 \%$ \\
\hline & S3 & 103 & 855.2 & 218.5 & 8456.2 & 1627.9 & $6.3 \%$ & 11201.7 & $4.8 \%$ \\
\hline & & & & & & \multicolumn{2}{|c|}{ Sum delivery costs } & 43793.8 & \\
\hline \multirow{6}{*}{ 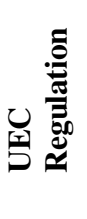 } & So & 100 & 838.1 & 178.6 & 8574.7 & 1583.3 & & 11014.8 & \\
\hline & S1 & 100 & 850.5 & 188.9 & 8542.7 & 1587.4 & $0.3 \%$ & 11132.2 & $1.1 \%$ \\
\hline & $\mathrm{S} 2$ & 101 & 860.1 & 195.8 & 8381.6 & 1572.4 & $-0.7 \%$ & 11212.5 & $1.8 \%$ \\
\hline & S3 & 108 & 930.2 & 218.0 & 8438.9 & 1624.4 & $2.6 \%$ & 12004.5 & $9.0 \%$ \\
\hline & & & & & & \multicolumn{2}{|c|}{ Sum delivery costs } & 45364.1 & \\
\hline & & & & & & & $\Delta$ & $3.6 \%$ & \\
\hline \multirow{6}{*}{ ن } & So & 100 & 862.8 & 177.0 & 8498.3 & 1569.2 & & 11247.6 & \\
\hline & S1 & 101 & 880.8 & 189.7 & 8439.0 & 1572.1 & $0.2 \%$ & 11427.4 & $1.6 \%$ \\
\hline & S2 & 103 & 900.1 & 199.4 & 8537.4 & 1601.6 & $2.1 \%$ & 11660.4 & $3.7 \%$ \\
\hline & S3 & 109 & 921.6 & 222.6 & 8627.9 & 1660.1 & $5.8 \%$ & 11964.0 & $6.4 \%$ \\
\hline & & & & & & \multicolumn{2}{|c|}{ Sum delivery costs } & 46299.4 & \\
\hline & & & & & & & $\Delta$ & $5.7 \%$ & \\
\hline
\end{tabular}




\section{Conclusions}

Companies need to consider different restrictions, such as traffic congestion and regulations, when producing vehicle schedules. Congestion is unlikely to diminish in the near future, and more stringent regulations designed to mitigate the negative externalities of freight transport are unavoidable. The regulations include restrictions on driving hours that limit driving time and working time according to the vehicle type (VOSA, 2011). This research introduces an LNS algorithm capable of producing high-quality solutions for the rich VRP variant that considers time windows, time-dependent travel times and rules on driving hours. A previous formulation for this variant did not exploited the early and split breaks that rules on driving hours allows, instances considering this issue are introduced. The LNS algorithm is able to study the last-mile problem found in home delivery considering city logistics (congestion, regulations, cost and environmental impact).

The LNS algorithm proposed in this research requires 2 min to produce solutions that substantially improve best-known solutions for the studied variant for instances of 100 customers; the results decrease the number of vehicles, the travelled distance and the route duration and it shows the importance of considering early and split breaks. Additionally, this research introduces benchmark values for The Road Transport (Working Time) Regulation 2005 in the UK.

The proposed LNS algorithm makes use of a Scheduler algorithm to accommodate breaks in order to satisfy the rules on driving hours, which is a heuristic based method specially tailored to be incorporated into LNS movements. It is capable of producing solutions with up to $19 \%$ less vehicles, $17.7 \%$ less distance and $4.4 \%$ less route duration. In an industry recognized for its low profit margin, as is the freight industry, this type of research is urgently need to provide solutions that satisfy regulation at a minimum cost and environmental impact. Further research could be proposed in order to test the many different procedures that can be created to accommodate breaks considering the trade-off between the benefits of imposing early breaks and the computational resources needed in the evaluation process.

Although extensive analysis could be proposed regarding the impacts of routing decisions in the supply chain, this research presented the benefits of algorithm research based on the industry needs. The presented analysis shows the impacts of the length of the time window at different levels of customer density in a $400 \mathrm{~km}^{2}$ territory in terms of delivery costs and emissions. By estimating the fuel consumption according to the average speed and vehicle type as proposed by the DFT (2014), imposing a $1 \mathrm{~h}$ time window with 100 customers increases the cost by $74 \%$ and increases the $\mathrm{CO}_{2}$ emissions by $196 \%$ compared to a service with no time windows. The cost of accommodating the rules on driving hours is around 3\%, and compliance with The Road Transport (Working Time) Regulation 2005 adds an additional 2\% increase in cost.

The impacts of congestion in the studied logistic configurations show the relation between the level of congestion and logistics costs: a congestion level of 2 (where the speed during peak times is reduced by a factor of 1.4 compared to a free-flow state) imposes an extra cost of $9 \%$. Further analysis of the results shows the impacts of service time on this type of operation. In the proposed scenarios, the service time was set to 6 min, where the driver would spend a large portion of their day in the doorways of customers; in the scenario with 400 customers, this would take approximately $75 \%$ of their time, and the average number of deliveries per vehicle per day is 69. In this scenario, the total time per route spent in service time is 6.8 hours out of approximately 9 hours of route duration per vehicle. This shows the importance of the training and experience of drivers to reduce the service time per delivery in multi-drop operations, such as parcel delivery or online groceries.

In recent years, the media has stated that deliveries of online groceries are unviable with logistics costs per delivery of $£ 20^{2}$ and that brick-and-mortar customers subsidize online shoppers. However, the analysis of the results in this research shows the importance of the length of the time window and the customer density: costs can be as low as $£ 1.4$ with no time window or $£ 1.8$ with a $2 \mathrm{~h}$ time window or as high as $£ 2.9$ with a $1 \mathrm{~h}$ time window with low customer density. These values are not intended to be representative of the industry, but they are an example of how to use algorithms to calculate delivery costs. The use of algorithms with high accuracy for rich VRP variants may help the industry to support logistics operations and to improve the design of the supply chain to provide better solutions according to the specific characteristics of the business model.

As previously mentioned, additional analysis could be proposed to study other issues in delivery operations with the algorithm proposed in this research: i) delivery cost structure and the relations among the length of the time window, congestion and customer locations; ii) the impacts of the depot location, for which the fast execution time of the algorithm can be used to run simulations; and iii) the impacts of vehicle selection. However, these analyses are beyond the scope of this research, which intended to show the relevance of developing such an algorithm.

\footnotetext{
${ }^{2}$ Daily Mail http://www.dailymail.co.uk/news/article-2707071/Supermarket-giants-lose-100million-yearonline-delivery-services-Cost-delivery-means-effectively-paying-customers-shop-them.html. Accessed on 0409-2015.
} 


\section{Appendix A: Travel time function}

The travel time between any two given customers $\left\{v_{i}, v_{j}\right\}$ depends on the travel speed function, specific data format and departure time from $v_{i}$. The following algorithm proposed by Ichoua et al. (2003) with notation presented by Figliozzi (2012) returns the arrival time $\mathrm{a}_{\mathrm{j}}$ to $v_{j}$ when departing from $v_{i}$ at departure rime $\mathrm{b}_{\mathrm{i}}$ :

\section{Data:}

$\mathrm{T}=\mathrm{T}_{1}, \mathrm{~T}_{2}, \ldots, \mathrm{T}_{\mathrm{p}}$ where each period $\mathrm{T}_{\mathrm{k}}$ has an associated constant travel speed $\mathrm{s}_{\mathrm{k}}$, an initial time $t_{\underline{k}}$ and a final time $t_{\bar{k}}$

$$
\begin{aligned}
& \text { Start } \\
& \text { if } a_{i}<e_{i} \text { then } \\
& b_{i} \leftarrow e_{i}+g_{i} \\
& \text { else } \\
& b_{i} \leftarrow a_{i}+g_{i} \\
& \text { endif }
\end{aligned}
$$

find $\mathrm{k}$ where $t_{\underline{k}} \leq \mathrm{b}_{\mathrm{i}} \leq \mathrm{t}_{\overline{\mathrm{k}}}$

$$
\begin{aligned}
& \mathrm{a}_{\mathrm{j}} \leftarrow \mathrm{b}_{\mathrm{i}}+\mathrm{d}_{\mathrm{ij}} / \mathrm{s}_{\mathrm{k}} \\
& \mathrm{d} \leftarrow \mathrm{d}_{\mathrm{ij},} \mathrm{t} \leftarrow \mathrm{b}_{\mathrm{i}} \\
& \text { while } \mathrm{a}_{\mathrm{j}}>\mathrm{t}_{\overline{\mathrm{k}}} \text { do } \\
& \mathrm{d} \leftarrow \mathrm{d}-\left(\mathrm{t}_{\overline{\mathrm{k}}}-\mathrm{t}\right) \mathrm{s}_{\mathrm{k}} \\
& \mathrm{t} \leftarrow \mathrm{t}_{\overline{\mathrm{k}}} \\
& \mathrm{a}_{\mathrm{j}} \leftarrow \mathrm{t}+\mathrm{d} / \mathrm{s}_{\mathrm{k}+1} \\
& \mathrm{k} \leftarrow \mathrm{k}+1 \\
& \text { end while }
\end{aligned}
$$

Return: $a_{j}$

End

\section{References}

Boyer, K. K., Prud'homme, A. M., \& Chung, W. (2009). The last mile challenge: evaluating the effects of customer density and delivery window patterns. Journal of Business Logistics, 30(1), 185-201.

Bräysy, O., \& Hasle, G. (2014). Software Tools and Emerging Technologies for Vehicle Routing and Intermodal Transportation. Vehicle Routing: Problems, Methods, and Applications, 18, 351.

Cattaruzza, D., Absi, N., Feillet, D., \& González-Feliu, J. (2015). Vehicle routing problems for city logistics. EURO Journal on Transportation and Logistics, 1-29.

Commercial-Vehicle-Engineer. (2012). More question marks over home-delivery safety.

Cordeau, J.-F., Gendreau, M., Laporte, G., Potvin, J.-Y., \& Semet, F. (2002). A guide to vehicle routing heuristics. Journal of the Operational Research society, 53(5), 512-522.

Chang, Y. S., Lee, Y. J., \& Choi, S. B. (2015). More Traffic Congestion in Larger Cities?-Scaling Analysis of the Large 101 US Urban Centers.

Dabia, S., Ropke, S., Van Woensel, T., \& De Kok, T. (2013). Branch and price for the time-dependent vehicle routing problem with time windows. Transportation science, 47(3), 380-396.

Dantzig, G. B., \& Ramser, J. H. (1959). The truck dispatching problem. Management science, 6(1), 80-91.

DFT. (2014). WebTag Databook.

Donati, A. V., Montemanni, R., Casagrande, N., Rizzoli, A. E., \& Gambardella, L. M. (2008). Time dependent vehicle routing problem with a multi ant colony system. European journal of operational research, 185(3), 1174-1191. 
Drexl, M. (2012). Rich vehicle routing in theory and practice. Logistics Research, 5(1-2), 47-63.

Dullaert, W., Janssens, G., Sörensen, K., \& Vernimmen, B. (2002). New heuristics for the fleet size and mix vehicle routing problem with time windows. Journal of the Operational Research society, 1232-1238.

Eglese, R., Maden, W., \& Slater, A. (2006). A road timetableTM to aid vehicle routing and scheduling. Computers \& operations research, 33(12), 3508-3519.

Ehmke, J. F., Steinert, A., \& Mattfeld, D. C. (2012). Advanced routing for city logistics service providers based on time-dependent travel times. Journal of Computational Science, 3(4), 193-205.

European-Commission. (2009). Report on an Action Plan on Urban Mobility. Retrieved from

Figliozzi, M. A. (2008). An iterative route construction and improvement algorithm for the vehicle routing problem with soft and hard time windows. Paper presented at the Applications of Advanced Technologies in Transportation (AATT) 2008 Conference Proceedings, Athens, Greece, May 2008.

Figliozzi, M. A. (2012). The time dependent vehicle routing problem with time windows: Benchmark problems, an efficient solution algorithm, and solution characteristics. Transportation Research Part E-Logistics and Transportation Review, 48(3), 616-636. doi:DOI 10.1016/j.tre.2011.11.006

Fleischmann, B., Gietz, M., \& Gnutzmann, S. (2004). Time-varying travel times in vehicle routing. Transportation science, 38(2), 160-173.

FTA. (2014). FTA's Manager's Guide to Distribution Costs'-October 2014 Update Report.

Gehring, H., \& Homberger, J. (1999). A parallel hybrid evolutionary metaheuristic for the vehicle routing problem with time windows. Paper presented at the Proceedings of EUROGEN99.

Gendreau, M., Ghiani, G., \& Guerriero, E. (2015). Time-dependent routing problems: A review. Computers \& operations research, 64, 189-197.

Gevaers, R., Van de Voorde, E., \& Vanelslander, T. (2011). Characteristics and typology of last-mile logistics from an innovation perspective in an urban context. City distribution and urban freight transport: multiples perspectives, 56-71.

Goel, A. (2009). Vehicle scheduling and routing with drivers' working hours. Transportation science, 43(1), 1726.

Goel, A., \& Vidal, T. (2013). Hours of service regulations in road freight transport: an optimization-based international assessment. Transportation science, 48(3), 391-412.

Gromicho, J., van Hoorn, J. J., Kok, A. L., \& Schutten, J. M. (2012). Restricted dynamic programming: a flexible framework for solving realistic VRPs. Computers \& operations research, 39(5), 902-909.

Haghani, A., \& Jung, S. (2005). A dynamic vehicle routing problem with time-dependent travel times. Computers \& operations research, 32(11), 2959-2986.

Hallamaki, A., Hotokka, P., Brigatti, J., Nakari, P., Bräysy, O., \& T, R. (2007). Vehicle Routing Software: A Survey and Case Studies with Finish Data. Technical Report. Retrieved from Finland:

Harwood, K., Mumford, C., \& Eglese, R. (2013). Investigating the use of metaheuristics for solving single vehicle routing problems with time-varying traversal costs. Journal of the Operational Research society, 64(1), 34-47.

Ichoua, S., Gendreau, M., \& Potvin, J.-Y. (2003). Vehicle dispatching with time-dependent travel times. European journal of operational research, 144(2), 379-396.

Javelin-Group. (2011). How many stores will we really need? UK non-food retailing in 2020. Retrieved from

Jensen, A., \& Dahl, S. (2009). Truck drivers hours-of-service regulations and occupational health. Work: A Journal of Prevention, Assessment and Rehabilitation, 33(3), 363-368.

Kok, A., Hans, E., \& Schutten, J. (2012). Vehicle routing under time-dependent travel times: the impact of congestion avoidance. Computers \& operations research, 39(5), 910-918.

Kok, A., Hans, E., Schutten, J., \& Zijm, W. (2010). A dynamic programming heuristic for vehicle routing with time-dependent travel times and required breaks. Flexible services and manufacturing journal, 22(1-2), 83-108.

Lunce, S. E., Lunce, L. M., Kawai, Y., \& Maniam, B. (2006). Success and failure of pure-play organizations: Webvan versus Peapod, a comparative analysis. Industrial Management \& Data Systems, 106(9), 1344-1358.

Malandraki, C. (1989). Time dependent vehicle routing problems: Formulations, solution algorithms and computational experiments. Retrieved from

Malandraki, C., \& Daskin, M. S. (1992). Time dependent vehicle routing problems: Formulations, properties and heuristic algorithms. Transportation science, 26(3), 185-200.

Mancini, S. (2014). Time dependent travel speed vehicle routing and scheduling on a real road network: the case of Torino. Transportation Research Procedia, 3, 433-441.

Mancini, S. (2017). A combined multistart random constructive heuristic and set partitioning based formulation for the vehicle routing problem with time dependent travel times. Computers \& operations research, $88,290-296$. 
Montero, A., Méndez-Díaz, I., \& Miranda-Bront, J. J. (2017). An integer programming approach for the timedependent traveling salesman problem with time windows. Computers \& operations research, 88, 280289.

Onghena, E. (2008). Integrators: werkwijze, strategieën en toekomst. Universiteit Antwerpen.

OR/MS-Today. (2016). Vehicle routing software survey. Retrieved from http://www.ormstoday.org/surveys/Vehicle_Routing/vrss.html

Pisinger, D., \& Ropke, S. (2007). A general heuristic for vehicle routing problems. Computers \& operations research, 34(8), 2403-2435.

Pisinger, D., \& Ropke, S. (2010). Large neighborhood search Handbook of metaheuristics (pp. 399-419): Springer.

Prescott-Gagnon, E., Desaulniers, G., Drexl, M., \& Rousseau, L.-M. (2010). European driver rules in vehicle routing with time windows. Transportation science, 44(4), 455-473.

Rincon-Garcia, N., Waterson, B., \& Cherrett, T. (2017). A hybrid metaheuristic for the time-dependent vehicle routing problem with hard time windows. International Journal of Industrial Engineering Computations, 8(1), 141-160.

Ring, L. J., \& Tigert, D. J. (2001). Viewpoint: the decline and fall of Internet grocery retailers. International Journal of Retail \& Distribution Management, 29(6), 264-271.

Ropke, S., \& Pisinger, D. (2006). An adaptive large neighborhood search heuristic for the pickup and delivery problem with time windows. Transportation science, 40(4), 455-472.

Solomon, M. M. (1987). Algorithms for the Vehicle Routing and Scheduling Problems with Time Window Constraints Operations Research, 35(2), 254-265.

Taniguchi, E., \& Thompson, R. (2002). Modeling city logistics. Transportation Research Record: Journal of the Transportation Research Board(1790), 45-51.

Taniguchi, E., Thompson, R. G., Yamada, T., \& Van Duin, R. (2001). City Logistics. Network modelling and intelligent transport systems.

TomTom. (2015). Traffic index. Retrieved from www.tomtom.com

US-DOT. (2004). Department Of Transport, Traffic Congestion and Reliability: Linking Solutions to Problems. Retrieved from http://www.ops.fhwa.dot.gov/congestion_report_04/chapter3.htm

Vidal, T., Crainic, T. G., Gendreau, M., \& Prins, C. (2013). A hybrid genetic algorithm with adaptive diversity management for a large class of vehicle routing problems with time-windows. Computers \& operations research, 40(1), 475-489.

Vidal, T., Crainic, T. G., Gendreau, M., \& Prins, C. (2014). A unified solution framework for multi-attribute vehicle routing problems. European journal of operational research, 234(3), 658-673.

Visser, J., Nemoto, T., \& Browne, M. (2014). Home delivery and the impacts on urban freight transport: A review. Procedia-social and behavioral sciences, 125, 15-27.

VOSA. (2011). Rules on Drivers' hours and tachographs. Retrieved from https://www.gov.uk/government/uploads/system/uploads/attachment_data/file/208091/rules-ondrivers-hours-and-tachographs-goods-vehicles-in-gb-and-europe.pdf

Yang, X., Strauss, A. K., Currie, C. S., \& Eglese, R. (2014). Choice-based demand management and vehicle routing in e-fulfillment. Transportation science, 50(2), 473-488. 